\title{
Reflexões e pesquisas sobre variação, mudança e estabilidade sob uma perspectiva construcional
}

\author{
Nahendi Almeida MOTA (D) \\ Universidade Federal do Rio de Janeiro (UFRJ)
}

RESUMO

Esta é uma resenha da mesa-redonda Gramática de Construções: estabilidade, variação e mudança, composta pelos professores Marcia dos Santos Machado Vieira, Edson Rosa Francisco de Souza e Taísa Peres de Oliveira, coordenada por Marcos Luiz Wiedemer. Na atividade, que ocorreu no dia 18 de julho de 2020, promovida pelo evento Abralin Ao Vivo, a fim de dar conta dos três tópicos centrais da mesa - estabilidade, variação e mudança - foram expostos resultados de pesquisas que têm sido desenvolvidas no Brasil, fundamentadas na abordagem construcionista, que compreende a construção como um pareamento convencionalizado de forma e

EDITADO POR Raquel Freitag

AVALIADO POR Marcos Wiedemer

DATAS significado, como unidade simbólica. Ficou evidente o alcance que essa abordagem já tem em nosso país, sobretudo no tocante à variação e à mudança.

\section{ABSTRACT}

This is a review of the Construction Grammar: stability, variation and change roundtable, composed by professors Marcia dos Santos Machado Vieira, Edson Rosa Francisco de Souza and Taísa Peres de Oliveira, coordinated by Marcos Luiz Wiedemer. In the activity, which occurred on July 18, 2020, promoted by the Abralin Ao Vivo event, in order to cover the three central topics of the discussion - stability, variation and change - the results of researches that have been developed in Brazil, based on the constructionist approach, which understands construction as a conventionalized pairing of form and meaning, as symbolic unit, were exposed. The 


\section{REVISTA DA ABRALIN}

scope that this approach already has in our country was evident, especially with regard to variation and change.

\section{PALAVRAS-CHAVE}

Gramática de Construções. Variação. Mudança.

\section{KEYWORDS}

Construction Grammar. Variation. Change.

Na mesa-redonda, intitulada Gramática de Construções: estabilidade, variação e mudança, composta pelos professores-pesquisadores Marcos Luiz Wiedemer (UERJ), Marcia dos Santos Machado Vieira (UFRJ), Edson Rosa Francisco de Souza (UNESP) e Taísa Peres de Oliveira (UFMS), apresentaram-se discussões de análises fundamentadas na abordagem da Gramática de Construções. Nesta, a língua é compreendida, conforme Traugott e Trousdale (2013, p. 1), como uma rede de relações entre construções, e estas são definidas como "unidades simbólicas convencionais", uma vez que, por serem compartilhadas entre falantes, passam a gerar um pareamento entre forma (propriedades fonéticas, morfológicas, sintáticas) e significado (propriedades semânticas, pragmáticas, discursivas) na mente do falante.

Para iniciar a mesa-redonda, Marcos Luiz Wiedemer apresentou um panorama de três momentos, não-excludentes, da Gramática de Construções. No primeiro, na década de 80, pesquisadores dedicavam-se aos fenômenos de estabilidade/sistematicidade e à descrição sincrônica; no segundo, já no século XXI, eles passaram a tratar da mudança linguística e a incorporar a descrição diacrônica, bem como métodos de análise oriundos da Linguística de Corpus; e, no terceiro, mais atual, os pesquisadores deram espaço à variação, à metodologia experimental e à discussão de conceitos teórico-metodológicos.

Quanto à variação, um dos tópicos fulcrais da mesa, foi denunciado o seu status, central ou periférico, a depender da visão do(a) pesquisador(a), que pode ou não considerar o caráter heterogêneo da língua. Todavia, mesmo que a visão adotada seja idealizada, aquela que entende a língua como homogênea, a natureza heterogênea desta sobressairá diante do(a) pesquisador(a). Essa afirmação vai ao encontro do que declaram Leino e Östman (2005), para quem não é possível ignorar a variação, no âmbito da Gramática de Construções, se o objetivo desta abordagem for lidar com todas as construções de uma língua, sejam elas centrais ou periféricas.

No Brasil, já há diversas pesquisas sendo feitas visando ao tratamento e à descrição de dados capazes de ilustrar a variação sob uma perspectiva construcional, a exemplo dos trabalhos desenvolvidos e orientados por dois dos palestrantes, Marcos Wiedemer e Marcia Machado (cf. MACHADO VIEIRA; WIEDEMER, 2018, 2019, WIEDEMER; MACHADO VIEIRA, 2018). Ambos têm levantado discussões que envolvem a variação tanto no que tange à competição quanto no que diz respeito à convivência entre variantes, isto é, alternativas licenciadas pela rede de que elas fazem parte. Para isso, eles têm trabalhado a variação a partir de duas premissas: (i) variação por analogia/alinhamento de construções independentes; e (ii) 


\section{REVISTA DA ABRALIN}

variação por compatibilização de (co)lexemas a slots de construção. Para tal, Machado Vieira e Wiedemer (a sair) apresentam as seguintes metodologias para o tratamento da variação no âmbito da Gramática de Construções: (i) por semelhança simbólica; (ii) por paradigma discursivo; e (iii) e por aloconstrução e metaconstrução, a qual recebeu destaque em suas falas.

A variação por aloconstrução e metaconstrução corresponde a possibilidades de representação, "por comparabilidade, relação de similaridade configuracional ou de semelhança simbólica entre constructos/usos licenciados por dois ou mais padrões construcionais do sistema, com base num alinhamento de atributos (de forma e/ou função) destes" (WIEDEMER; MACHADO VIEIRA, 2018, p. 48). Em outras palavras, conforme Cappelle (2006), é a maneira de conceber dois padrões, não como um derivado do outro, mas, sim, como realizações variantes de uma construção parcialmente subespecificada, ou seja, como aloconstruções. E a metaconstrução, por sua vez, é o constructo teórico que representa a neutralização de diferenças e a conceptualização de semelhanças.

Marcia Machado, em sua apresentação intitulada Variação construcional: perspectiva e realidade, tratou da variação como um assunto que tem gerado provocações e pesquisas. Para dissertar sobre as provocações, ela trouxe, entre outros pontos de discussão, as concepções de (a) envelope de variantes, ideia de mesmo valor de verdade entre unidades diferentes, entendendo a variação como inerente à língua; (b) comparabilidade funcional, como condição para o estudo; (c) princípio da nãosinonímia, quando indaga, no espaço da Gramática de Construções, se é possível falar de variação e considerar tal princípio ao mesmo tempo; (d) iconicidade, questionando essa relação de um-paraum, de uma forma para apenas um significado semântico ou pragmático; e (e) arbitrariedade.

Já na exposição das pesquisas, para tratar da compatibilização entre variantes, das similaridades e diferenças e de fatores funcionais e formais, ela exibiu, sobretudo, estudos em desenvolvimento no projeto Predicar - Formação e expressão de predicados complexos e predicações, desde Machado Vieira (2016). Muitas destas pesquisas têm-se dedicado à variação como um dos pontos centrais, a exemplo de dois estudos ${ }^{1}$, um sobre construções [verbo suporte(-se) (uma) de/por X], acerca dos verbos suportes dar, fazer, passar, posar e tirar seguidos de elemento nominal preposicionado, e outro sobre construções intensificadoras X de Y, em que o slot X é preenchido por um lexema de cor, como em roxo/verde de raiva ou vermelho de vergonha. Nestas e em outras pesquisas do projeto, variados tipos de análise têm sido utilizados, como a análise de frequência, a multivariada (KLAVAN, 2012), a colostrucional (STEFANOWITSCH, 2013) e, ainda, pesquisas experimentais.

Edson Rosa destinou sua fala à apresentação do trabalho intitulado Um estudo diacrônico da microconstrução intensificadora [[x] pra caramba] no português. Antes de tudo, ele respondeu à seguinte pergunta: "O que move o falante?". Sua resposta foi direcionada ao tratamento da intensificação, o que o levou a afirmar que nós, falantes, fazemos avaliações, sejam elas intensificadas ou não, sobre o que nos cerca, como pessoas, sentimentos e lugares, característica fundamental e presente nas mais diversas situações comunicativas. Ele também afirmou que olhar a língua sob a perspectiva

1 Pesquisas desenvolvidas, respectivamente, por Jeane Nunes da Penha, no mestrado, e por Nahendi Almeida Mota, no doutorado, ambas sob a orientação da professora Marcia dos Santos Machado Vieira. 


\section{REVISTA DA ABRALIN}

baseada no uso é entender que a estrutura linguística reflete a estrutura da experiência/da perspectiva de mundo do falante. Vale destacar, partindo de sua afirmação, que, mais do que refletir as experiências dos falantes, a língua também gera sentidos e contribui para essa experienciação.

Seu objetivo foi analisar, com base nos pressupostos da abordagem construcional, a microconstrução intensificadora [[x] pra caramba], instanciada pelo subesquema $[[\mathrm{x}]$ Prep+N], o que o motivou a (i) verificar as motivações formais e funcionais que leva(ra)m o falante a escolher essa microconstrução perifrástica em vez de uma simples para intensificar e (ii) analisar o processo de mudança construcional, tendo em vista a esquematicidade, a composicionalidade e a produtividade. Deste trabalho, vale destacar, entre outros pontos, (a) as observações acerca das construções simples e perifrásticas e sua relação com a gradação da intensidade e o tratamento da intensidade hiperbólica, já que há intensificação em ambas, embora em graus diferentes; (b) o fato de a construção [[x] pra caramba], com base nos dados do Corpus do Português, ser uma estratégia de intensificação recente, considerada inovadora na língua; e (c) essa construção é pouco estigmatizada se comparada a [[x] pra caralho], bastante marcada, e [[x] pra cacete], de forma mediana.

Chegou-se à conclusão, assim, que, quanto às propriedades formais, tal construção é fixa, pois costuma posicionar-se à direita do elemento por ela modificado; não admite flexão de número, gênero e pessoa, e seu uso no diminutivo e no aumentativo é bem pouco produtivo; e a preposição [para] aparece, quase sempre, em sua forma reduzida [pra]. Já no tocante às propriedades funcionais, o autor afirmou que a construção [pra caramba] pode atuar como intensificadora modificando verbos, advérbios, adjetivos, nomes e orações, transmitindo um valor positivo. Além disso, sua frequência é maior em gêneros textuais de notícia e matérias de jornal que apresentam contextos de interação orais.

Taísa Peres, por fim, definiu como objetivo, em sua fala intitulada Modelos de rede no tratamento das condicionais, apresentar uma rede construcional que considerasse que as redes podem emergir, expandir, reorganizar-se. Para tanto, ela expôs características do modelo vertical de heranças e do modelo de rede horizontal, a fim de mostrar que a associação entre ambos é mais efetiva do que o tratamento de apenas um deles. Segundo o primeiro modelo, elaborado por Goldberg $(1995,2006)$, as construções são baseadas em generalizações de enunciados reais, e a rede é vista como uma organização de esquemas, subesquemas, microconstruções e construtos. E, de acordo com o segundo modelo, proposto por Velde (2014), esquemas e subesquemas não representam expressões discretas; na verdade, uma construção pode ser parcialmente motivada pelos seus vizinhos.

A participante ilustrou a associação entre esses modelos, utilizando a categoria das condicionais em português, sinalizando que esta lista não é facilmente fechada. Ela destacou, também, as vantagens em trabalhar com ambos os modelos, como a possibilidade de (i) explicar a funcionalidade como resultado do uso de itens que instanciam esquemas já existentes; (ii) mostrar que subesquemas podem herdar propriedades também de subesquemas vizinhos, e não apenas dos níveis hierarquicamente mais altos; e (iii) compreender que é possível lidar com um modelo de rede multidimensional, a fim de explicar a relação entre os diferentes domínios semânticos e pragmáticos que sustentam uma determinada construção. 


\section{REVISTA DA ABRALIN}

Por meio de tais apresentações, das pesquisas que lhes serviram de base e estão situadas no momento mais atual da Gramática de Construções, ficou evidente que a variação tem recebido destaque, os conceitos teóricos-metodológicos têm sido questionados e ampliados e pesquisas experimentais também já estão sendo planejadas e elaboradas. Logo, a mesa ilustrou o quão ricas e pertinentes têm sido as contribuições da perspectiva construcional para o tratamento da variação e da mudança, ambas características inerentes à língua.

\section{REFERÊNCIAS}

CAPPELLE, Bert. Particle placement and the case for "allostructions". Constructions, Special Volume 1, 2006, p. 1-28.

GOLDBERG, Adele E. Constructions: a construction grammar approach to argument structure. Chicago, The University of Chicago Press, 1995.

GOLDBERG, Adele E. Constructions at work: the nature of generalization in language. Oxford: Oxford University Press, 2006.

GRAMÁTICA de construções: estabilidade, variação e mudança. Mesa-redonda apresentada por Marcia dos Santos Machado Vieira, Edson Rosa Francisco de Souza e Taísa Peres de Oliveira, sob coordenação de Marcos Luiz Wiedemer, 2020. 1 vídeo (2hs24min 44s). Publicado pelo canal da Associação Brasileira de Linguística em: https://www.youtube.com/watch?v=zADzJHQkn8Y. Acesso em: 20 set. 2020.

KLAVAN, Jane. Evidence in linguistics: corpus-linguistic and experimental methods for studying grammatical synonymy. Institute of Estonian and General Linguistics - University of Tartu, 2012, 286p.

LEINO, Jaakko; ÖSTMAN, Jan-Ola. Construction and variability. In: FRIED, Mirjam; BOAS, Hans C. Grammatical Construction. Back to the roots. Amsterdam/Philadelphia: John Benjamins Publishing Company, 2005, p. 191-213.

MACHADO VIEIRA, Marcia dos Santos. Variação e mudança na descrição construcional: complexos verbo-nominais. Revista Linguística, v. ESPECIAL, 2016, p. 152-170.

MACHADO VIEIRA, Marcia dos Santos; WIEDEMER, Marcos Luiz. Sociolinguística variacionista e Gramática de Construções: os desafios e as perspectivas de compatibilização. In.: MACHADO VIEIRA, Marcia dos Santos; WIEDEMER, Marcos Luiz (Orgs.). Dimensões e experiências em Sociolinguística. São Paulo: Blucher, 2019, p. 85- 120.

MACHADO VIEIRA, Marcia dos Santos; WIEDEMER, Marcos Luiz. Lexemas e construção: atração, coerção e variação. Caderno Seminal Digital Especial. n. 1 v. 1. (jan-dez/2018), p. 81-132. Disponível em: <https://www.e-publicacoes.uerj.br/index.php/cadernoseminal/article/download/34009/26432>. Acesso em: 27 jun. 2020.

MACHADO VIEIRA, Marcia dos Santos; WIEDEMER, Marcos Luiz. A variação no modelo construcionista da Linguística FuncionalCognitiva. In.: BRESCANCINI, C.; MONARETTO, V. N. O. Anais do XXXII ENANPOLL. Porto Alegre: PUC-RS (a sair).

STEFANOWITSCH, Anatol. Collostructional analysis. In: HOFFMAN, Thomas; TROUSDALE, Graeme (Eds.). The Oxford Handbook of Construction Grammar, 2013.

TRAUGOTT, Elizabeth Closs; TROUSDALE, Graeme. Constructionalization and Constructional Change. Oxford University Press: Oxford, 2013. 


\section{REVISTA DA ABRALIN}

VAN DE VELDE, Freek. Degeneracy: The maintenance of constructional networks. In: BOOGAART, Ronny; COLLEMAN, Timothy; RUTTEN, Gijsbert (Eds.) Extending the scope of Construction Grammar. Berlin: De Gruyter Mounton, 2014, p. 141-179.

WIEDEMER, Marcos Luiz; MACHADO VIEIRA, Marcia dos Santos. Sociolinguística e gramática de construções: o envelope da variação. In: FRANCESCHINI, Lucelene Teresinha; LOREGIAN-PENKAL, Loremi. (Orgs.). Sociolinguística: estudos de variação, mudança e atitudes linguísticas. Guarapuava. Ed. da Unicentro, 2018, p. 41-77. 